\section{Libertad de Expresión en Venezuela}

\author{
Eduardo Andrés Bertoni*
}

Este comentario, junto a los documentos que analiza, está disponible en www.anuariocdh.uchile.cl

En el año 2007, la discusión sobre la libertad de expresión en América Latina fue vibrante. Por ejemplo, varias de las organizaciones no gubernamentales, que en la ciudad de Washington DC se ocupan de la región, Ilevaron adelante foros específicamente vinculados con esa cuestión ${ }^{1}$. Casi siempre, y a pesar de que el tema principal de los encuentros era el análisis regional, la discusión finalizaba en un debate sobre la libertad de expresión en la República Bolivariana de Venezuela.

Sin embargo, analizar la libertad de expresión en una región desde la perspectiva de un solo país puede llevar a conclusiones equivocadas. Si se estudia América Latina desde un espacio temporal amplio, pueden constatarse varios avances que son beneficiosos para el ejercicio de la libertad de expresión y que eran impensables años atrás. Leyes de acceso a la información pública han sido aprobadas en muchos países. El delito de desacato ha sido derogado en otros o se encuentra en desuso. La utilización de los delitos de difamación criminal ha sido cuestionada como nunca cuando se aplica a expresiones vinculadas con asuntos de interés público. La jurisprudencia del Sistema Interamericano de Derechos Humanos es hoy una guía clara por donde los países deben transitar $^{2}$. Por supuesto que preocupa la violencia contra periodistas en ciertos países y la impunidad de la cual gozan sus autores materiales e intelectuales. También siguen desarrollándose juicios penales contra periodistas, defensores de derechos humanos, o incluso funcionarios públicos que critican al gobierno. Es una obviedad resaltar que queda mucho por hacer, pero analizar la materia desde la perspectiva de lo que ocurre en un solo país puede llevar a minimizar los importantes avances que han ocurrido en América Latina.

De todos modos, la derivación de la discusión desde una perspectiva general del tema a la situación en un determinado Estado no es casual. En Venezuela, el ambiente para el libre ejercicio de la libertad de expresión se ha deteriorado en los últimos años. Y la no renovación de la concesión a la empresa privada que explotaba comercialmente Radio Caracas Televisión (RCTV), cuya línea editorial era opositora al gobierno, alcanzó en 2007 la atención internacional ${ }^{3}$.

* Director Ejecutivo de la Fundación para el Debido Proceso Legal (DPLF), Washington D.C., EE.UU. Ex Relator Especial para la Libertad de Expresión de la Organización de Estados Americanos (OEA). Profesor de Derecho Penal y Procesal Penal, Universidad de Buenos Aires. Profesor Adjunto, Universidad George Washington.

1 Por ejemplo, "Members of Congress Discuss Press Freedom in Mexico and Colombia", organizado por el Inter American Dialogue (IAD), octubre de 2007 (ver http://www.thedialogue.org/page.cfm?pagelD=32\&publD=1064\&s=); "Press Freedom in Latin America: Moving Forward or Sliding Backwards?", IAD, julio de 2007 (ver, http://www.thedialogue.org/page. cfm?pagelD=32\&pubID=216\&s=); "Latinoamérica y Libertad de Prensa: Tiempos Difíciles", patrocinado por el Comité Internacional de Corresponsales del Club Nacional de la Prensa, julio de 2007.

2 Sobre la evolución de la jurisprudencia del Sistema Interamericano, ver Eduardo Bertoni, Libertad de Expresión en el Estado de Derecho (Segunda Edición), Editores Del Puerto, Buenos Aires, 2007, Capítulo VIII.

3 Por ejemplo, aún sin haber ingresado formalmente en la agenda de la Asamblea General de la Organización de los Estados Americanos (OEA) del año 2007, el tema de RCTV fue motivo de polémica en algunas sesiones, tal como quedó reflejado por los medios periodísticos que cubrieron el evento. 
Por un lado, el deterioro en el ejercicio de la libertad de expresión se venía advirtiendo con anterioridad al episodio de RCTV. Los ataques físicos a periodistas constatados por organismos internacionales de derechos humanos ${ }^{4}$-cuyo punto más alto se dio en el período 2002-2003, decayendo luego- ${ }^{5}$; la ausencia de investigaciones que determinaran los culpables de esos ataques -dicho de otro modo, la impunidad en la que persisten sus autores ${ }^{6}{ }^{6}$; los cambios legislativos impulsados por el gobierno directamente vinculados con el ejercicio de la libertad de expresión -por ejemplo, el nuevo Código Penal ${ }^{7}$ o la ley de responsabilidad social de radio y televisión-; la interpretación judicial de la legislación -interpretación muchas veces contraria a los estándares internacionales ${ }^{8}$; y finalmente, como mencioné, el cese de transmisión de un canal de televisión crítico del gobierno ocurrido en 2007, son las acciones más visibles que a lo largo de estos años han Ilevado a muchas organizaciones internacionales, gubernamentales y no gubernamentales, a expresar su preocupación por el ejercicio de la libertad de expresión en Venezuela.

Por otro lado, otras organizaciones -e incluso el propio gobierno-, han señalado que en Venezuela existe una amplia libertad de expresión y, para ello, argumentan que basta con leer los diarios o ver los noticieros para darse cuenta que en el país la crítica al gobierno es constante y, en muchos casos, sin precedente en otros lugares. Este es un argumento cuya constatación fáctica es sencilla para cualquiera que visita el país.

Frente a estas dos posiciones contradictorias, es necesario volver a reflexionar sobre la situación de la libertad de expresión en Venezuela.

El argumento de quienes consideran que el ejercicio de la libertad de expresión en Venezuela es vigoroso tiene una falla en su premisa inicial. Tal falla consiste en entender que sólo basta la libertad de crítica al gobierno para confirmar la existencia de un ambiente donde está garantizado el ejercicio de la libertad de expresión.

Obviamente que la libertad de crítica en asuntos de interés público es fundamental para afirmar un ambiente adecuado para la realización del derecho que es objeto de análisis en este trabajo.

4 Ver, a modo de ejemplo, el Informe de la Relatoría Especial para la Libertad de Expresión de la Comisión Interamericana de Derechos Humanos (CIDH), Capítulo № 2 sobre Venezuela, años 2002 y 2003. Ver también CIDH, "Informe sobre la Situación de Derechos Humanos en Venezuela", Capítulo VI.B, en http://www.cidh.org/countryrep/Venezuela2003sp/ cap.6.htm\#Amenazas.

5 La Corte Interamericana de Derechos Humanos, al dictar medidas provisionales de acuerdo a las atribuciones que le concede el art. 63.2 de la Convención Americana de Derechos Humanos (CADH) y el art. 25 de su Reglamento, en más de una oportunidad requirió a Venezuela medidas de protección a periodistas atacados y la investigación de los hechos. En 2007 se mantuvieron medidas decretadas con anterioridad. Ver http://www.corteidh.or.cr/docs/medidas/ globovision_se_02.doc.

6 Uno de los casos paradigmáticos es la muerte del reportero gráfico Jorge Tortoza mientras cubría el golpe de Estado ocurrido en abril de 2002. Hasta el presente el caso permanece impune.

7 En relación con las modificaciones del Código Penal y su impacto en el trabajo de periodistas, ver "El Peso de las Palabras, Procesos Judiciales y Libertad de Expresión en Venezuela 2002-2006", Espacio Público, Carlos Correa y Débora Calderón (Coords.), año 2007. Allí concluyen que: "La reforma del Código Penal publicada en la Gaceta Oficial de fecha 16 de marzo de 2005, Extraordinario N $\mathrm{N}^{\circ}$ 5.763, fortaleció la regresión en el contenido y garantía del Derecho Humano a la Libertad de Expresión e Información. Ratificó y profundizó el desacato o vilipendio contra funcionarios; aumentó la discrecionalidad de los jueces para decidir si una conducta o expresión encuadra en el tipo penal respectivo; y es discriminatoria al diferenciar al funcionario respecto de la persona, limitando el escrutinio ciudadano de la gestión pública" (p. 123).

8 Así, el fallo № 1942 de la Sala Constitucional del Tribunal Supremo de Justicia de la República Bolivariana de Venezuela del año 2003 convalidó los delitos conocidos como "desacato", que se encuentran en franca contradicción con la Convención Americana sobre Derechos Humanos. Es oportuno señalar que la CIDH casi diez años antes había hecho un análisis de la compatibilidad de las leyes de desacato con la mencionada Convención. La CIDH concluyó que tales leyes no eran compatibles con el Tratado porque se prestaban al abuso como medio para silenciar ideas y opiniones impopulares, reprimiendo de ese modo el debate que es esencial para el efectivo funcionamiento de las instituciones democráticas. 
Pero esta libertad no debe traer como consecuencia represalias arbitrarias. La existencia de un campo propicio para el ejercicio de la libertad de expresión no se puede medir a partir del grado de valentía periodística que requiera llevar adelante críticas cualquiera sea su costo. Un ambiente apropiado para dicho ejercicio es aquél donde la arquitectura institucional juega un papel fundamental, posibilitando la crítica sin temor a represalias arbitrarias.

También es evidente que ese temor a represalias por la expresión crítica, si se consolida y extiende en el tiempo, conduce a la autocensura. Sin embargo, conocer cuánto se ha dejado de criticar por temor a las consecuencias requiere una investigación prolongada, dado que la autocensura difícilmente ocurre de un día para el otro. Es un proceso lento, donde el coraje se resquebraja, los intereses cambian y, al final, la crítica disminuye. En otras palabras, si bien es cierto que constatar la crítica política por los medios de comunicación es sencillo, no es menos cierto que constatar la autocensura es una tarea difícil.

Lo que sí se puede corroborar rápidamente es la puesta en marcha de políticas públicas que pueden derivar en ese proceso de autocensura. Ello no quiere decir que la autocensura "ya" sea un hecho, pero tal constatación sirve para afirmar que el ambiente no es el más idóneo para el ejercicio de la libertad de expresión ${ }^{9}$.

Durante el año 2007, el cese de transmisiones por televisión abierta de RCTV, ocurrido a finales de mayo, fue objeto de preocupación de distintos sectores que entendieron que la decisión del gobierno de no renovar la licencia a ese medio constituía un atentado a la libertad de expresión en Venezuela ${ }^{10}$.

El caso de RCTV podría resumirse de manera sencilla. Por disposición a los acuerdos internacionales suscriptos en el ámbito de la Unión Internacional de Telecomunicaciones, los Estados tienen la administración del espectro radioeléctrico. Venezuela, como el resto de los países de la región, también administra el espacio del espectro que le corresponde a su territorio. En ese sentido, los derechos para su utilización -que se traducen en concesiones para la explotación de servicios de radio y televisión- son otorgados por el Estado de acuerdo a la legislación local y mediante contratos de concesión, de licencia o de otra naturaleza jurídica. Por un lado, el gobierno venezolano argumentó que el contrato de concesión de RCTV terminaba, y que la decisión era no renovarlo. Por el otro, RCTV planteó que la interpretación de la legislación pertinente a su contrato permitía afirmar que éste no vencía en la fecha indicada por el gobierno.

Hasta aquí, el problema podría ser entonces reducido a uno de mera interpretación legal, donde la opinión del Estado no coincide con la de los particulares. En una democracia, este tipo de diferencias se resuelven por canales institucionales; especialmente el Poder Judicial, que debe gozar de la independencia e imparcialidad necesarias. Lamentablemente, en Venezuela existen muchas sospechas sobre la verdadera existencia de estos atributos en el Poder Judicial. Incluso, la

9 Sin embargo, un reciente estudio realizado en Venezuela mediante entrevistas a periodistas, concluye que los juicios impulsados en su contra los ha llevado a replantearse "...si continuar o no de la misma manera el ejercicio profesional". Sostiene el estudio que: "El riesgo de incurrir en la autocensura propia o inducida está ahora con una presencia muy superior que en otras épocas según sus propias palabras. Están más conscientes de que representan un blanco vulnerable frente a las represalias de los funcionarios que utilizan los recursos establecidos en el Código Penal (vilipendio, difamación e injuria) vigilando el trabajo propio. También son conscientes de que los medios para los que trabajan pueden verse vulnerados por tales poderes e influencia y que les incumbe a ellos pues son parte de esa cadena de control". Ver "El Peso de las Palabras", Op. Cit., p. 115.

10 Así, en mayo de 2007, José Miguel Vivanco, director de las Américas de Human Rights Watch expresó que: “El Presidente Hugo Chávez está abusando de la autoridad regulatoria del Estado para castigar a un medio de comunicación por sus críticas al gobierno. La decisión de cerrar RCTV es una amenaza muy seria a la libertad de expresión en Venezuela". Ver http://hrw.org/spanish/docs/2007/05/22/venezu15991.htm. 
politización de las más altas instancias de la judicatura venezolana y su falta de independencia, han sido seriamente sostenidas por distintos sectores ${ }^{11}$.

La interpretación del contrato y de las normas correspondientes, por supuesto que no es una cuestión menor para resolver a quién le asiste la razón jurídica en la controversia. Pero en el contexto que atraviesa el Poder Judicial venezolano, parece insuficiente conformarse con sus decisiones, que vale destacar han sido hasta el momento contrarias a los intereses de RCTV.

Aun sin entrar a analizar los vericuetos de la ley y del contrato, los motivos que llevaron a la decisión de no renovar la concesión surgidos de las declaraciones de altos funcionarios permiten afirmar que hubo un manejo cuanto menos sospechoso de la administración del espectro electromagnético por parte del gobierno.

Como lo explica el Comité para la Protección de Periodistas (CPJ, por su sigla en inglés), "[f]uncionarios gubernamentales, desde el presidente hacia abajo, han acusado a RCTV de violar la Constitución y la normativa de radio y televisión, sin hablar de la colaboración con los autores de un golpe contra Chávez en el 2002". Sin embargo, sigue el informe, una investigación de tres meses del CPJ, "... revela que el gobierno no realizó una revisión imparcial y transparente del proceso de renovación de la concesión de RCTV. En cambio, según halló el CPJ, la evidencia apunta a una decisión tomada de antemano y motivada por razones políticas. El propio Chávez anunció la decisión en un discurso pronunciado el 28 de diciembre [de 2006], en el que afirmó que el gobierno no les renovaría la concesión a los 'golpistas' de RCTV. En los meses previos y siguientes al anuncio, el gobierno no efectuó audiencias públicas, no siguió ningún criterio explícito y no le proporcionó a RCTV la oportunidad de responder a las afirmaciones realizadas por altos funcionarios en conferencias de prensa, discursos y entrevistas" ${ }^{\prime 12}$.

No pasó desapercibida la entrevista dada al diario El Nacional el 8 de enero de 2007 por el Ministro de Comunicaciones, Andrés Izarra. A comienzos de año, había aclarado cuál era la política pública del gobierno en materia de su cartera; dijo el funcionario que: "Hay que elaborar un nuevo plan, y el que nosotros proponemos es que sea hacia la hegemonía comunicacional e informativa del Estado".

Por su parte, las conclusiones del estudio del CPJ son categóricas: “[...] en primer lugar, se anunció una decisión, y luego siguió una oleada de acusaciones públicas. Pero hasta hoy no ha existido un proceso de revisión imparcial y transparente donde la evidencia pueda ser sometida a escrutinio y el canal pudiera presentar su defensa. En lugar de ello, el registro refleja las acciones de un gobierno motivado, por consideraciones políticas, a suprimir la cobertura crítica. Debido a que las concesiones de muchas televisoras y emisoras de radio vencen este año, el caso de RCTV está llevando a otros medios a suavizar su cobertura y sacar del aire a programas con voces críticas. Al parecer, la administración Chávez pretende reemplazar lo que considera el dominio empresarial de las frecuencias por el dominio del Estado"13.

\footnotetext{
11 Ver, por ejemplo, las conclusiones del Informe de la Internacional Bar Asociation (IBA) "Venezuela: La justicia en entredicho", de junio de 2007: "La IBA concluye que el efectivo respeto y el desarrollo de los fines y funciones del Poder Judicial en Venezuela se encuentran hondamente afectados; sus dificultades van desde intervenciones directas de otros entes estatales en su trabajo hasta problemas sistémicos sin resolver. Las tres jurisdicciones más vulnerables son la Constitucional, la Contencioso Administrativa y la Penal, al tener el control del poder en su ejercicio positivo y represivo". Ver también las conclusiones de Human Rights Watch en http://hrw.org/spanish/docs/2004/12/14/venezu9870.htm.

12 Ver Carlos Lauría y Sauro González, "Estática en Venezuela", en http://www.cpj.org/Briefings/2007/DA_spring_07/ Venezuela_07/venezuela_07sp.html.

13 Ídem.
} 
Así, como adelantaba previamente, la autocensura como consecuencia de las acciones del Estado deja de ser una posibilidad para, de acuerdo al CPJ, convertirse en una realidad.

Para concluir, supongamos que la interpretación jurídica del gobierno es la correcta, que la concesión terminaba y que tal interpretación del contrato y de las normas en juego fue avalada correctamente por las instancias judiciales. Supongamos también que la motivación de no renovar la concesión ni dar la oportunidad a otros para que la exploten estuvo fundada en la necesidad de diseñar una nueva política de comunicación.

A partir de la salida del aire de RCTV, la porción del espectro radioeléctrico que explotaba fue ocupada por un canal público. El gobierno había manifestado que necesitaba recuperar el espacio radioeléctrico para utilizarlo de manera que estuviera de acuerdo con las nuevas políticas públicas en materia cultural. Sin perjuicio de las constantes contradicciones sobre los motivos, determinadas por el momento o por los actores (recordemos que el Presidente dijo que no se renovaba la concesión a RCTV por "golpistas"), podríamos preguntarnos si resultaba necesario, para la implementación de esas nuevas políticas públicas, recuperar esa frecuencia para su explotación por parte de un canal público.

Un rápido recuento de las frecuencias con las que contaba el Estado realizado por varias organizaciones ${ }^{14}$, permite también sospechar de la sinceridad de aquel propósito. En consecuencia, se afirma aún más la tesis sobre la manipulación arbitraria y discrecional del espectro radioeléctrico en beneficio de la "hegemonía comunicacional" del Estado, que había anticipado el hoy nuevamente Ministro Izarra.

La Asociación Mundial de Radios Comunitarias (AMARC), que viene defendiendo hace años la necesidad de una administración transparente del espectro radioeléctrico, fue muy explícita en su análisis sobre la no renovación de la concesión a RCTV. En un comunicado de prensa expresó que: "El gobierno de Venezuela ha señalado a RCTV y el grupo económico que lo controla de estar involucrado con los golpistas. En caso que el gobierno de Venezuela entendiera que es culpable de este delito, debería habilitar un proceso adecuado para investigar y enjuiciar a los eventuales responsables, brindando todas las garantías del debido proceso al que tienen derecho todas las personas, incluso los golpistas. De comprobarse tal acusación, ameritaría no sólo no renovar la concesión sino su directa revocación. AMARC considera que no es aceptable que se otorgue, cancele, renueve o no renueve el uso de frecuencias de radio y TV en función de la conveniencia o afinidad política con el gobierno de turno, especialmente cuando muchas veces es el propio gobierno quien cumple este papel y no organismos estatales independientes"15.

Tal como señaló esa organización, el Estado venezolano, como administrador del espectro radioeléctrico en su territorio, tiene la potestad de conceder frecuencias radioeléctricas para el uso de radio y TV, así como para evaluar la renovación o no de esas licencias, incluyendo la de RCTV. Sin embargo, los Estados no pueden administrar el uso de las frecuencias de manera discrecional

\footnotetext{
14 Ver, entre otros, las conclusiones de Human Rights Watch expresadas en el comunicado de prensa mencionado anteriormente: "El gobierno tiene frecuencias a su disposición en muchas partes de Venezuela, tanto en VHF como en UHF. Incluso, ha usado la frecuencia UHF para instalar con éxito un canal cultural y educativo, Vive TV".

15 Ver "Carta abierta sobre el caso RCTV en Venezuela", AMARC, abril de 2007, en http://www.sntp.org.ve/mayo0705. html. Es importante de destacar que AMARC, en la misma carta, también dejó plasmada su opinión sobre RCTV diciendo que: "Respecto a la situación de RCTV, AMARC deplora la actitud que tuvieron esta emisora y otros medios durante el Golpe de Estado de abril de 2002, violando el derecho a la información de los venezolanos en momentos cruciales para la democracia en su país. Su actitud y papel cuestionan el mismo principio que ahora aducen como argumentos en defensa de sus intereses frente al gobierno. La radio y la TV son espacios públicos en los que debe promoverse la responsabilidad social y el respeto por los valores democráticos y la pluralidad, así como a la libertad de recibir y buscar información, derecho que tienen todas las personas y que no puede ser por nadie coartado".
} 
ni arbitraria. Los máximos estándares interamericanos de derechos humanos establecen que el otorgamiento de frecuencias de radio y TV debe garantizar igualdad de oportunidades a todas las personas y sectores sociales, y que los requisitos, procedimientos y criterios de evaluación deben ser transparentes, claros y estar establecidos previamente, promoviendo un acceso equitativo a este recurso. Estos principios son válidos tanto para la concesión como para la renovación del uso de las frecuencias radioeléctricas ${ }^{16}$.

En definitiva, lo ocurrido con RCTV durante 2007 ha puesto en evidencia el diseño de una política pública, mediante una manipulación poco transparente del espectro radioeléctrico, para beneficio propio del gobierno y no de la ciudadanía. Y ello constituye una acción más que lesiona el ejercicio de la libertad de expresión en Venezuela.

16 Estos argumentos de AMARC son contestes con los que la Relatoría Especial Para la Libertad de Expresión de la CIDH, que había expresado en un informe sobre "Libertad de Expresión y Pobreza" en el año 2002: “...la Relatoría entiende que los Estados en su función de administradores de las ondas del espectro radioeléctrico deben asignarlas de acuerdo a criterios democráticos que garanticen una igualdad de oportunidades a todos los individuos en el acceso a los mismos. Esto precisamente es lo que establece el Principio 12 de la Declaración de Principios de Libertad de Expresión". Ver en http://www.cidh.oas.org/relatoria/showarticle.asp?artID=329\&IID=2. 